\title{
Smart grid infrastructure in Ireland: facilitating the energy transition
}

\author{
Orla Nic Suibhne*, Margaret Tallott \\ GREAT Project, Udarás na Gaeltachta, An Aislinn, Bóthar an tSéipéil, Béal an Mhuirthead, Co Mhaigh Eo, Ireland
}

\begin{abstract}
The twenty-first century is expected to bring challenges for energy systems across the globe. Most significantly the continued growth in worldwide population and increased use of consumer goods will create significantly greater electricity demand requirements, which must be met amidst pressures to reduce carbon emissions, retain security of supply and improve national cost competitiveness. It is indeed these challenges that have highlighted the importance of a clean, reliable electricity supply and encouraged many countries to invest in electricity grid infrastructure in an effort to move towards the development of a 'Smart Grid'. The requirement to develop an Irish smart grid has therefore been pushed up the energy policy agenda and has resulted in significant national commitments to investment in electricity system infrastructure. This paper investigates the current state of play with Smart Grid in Ireland, including the changing landscape in which distributed energy generation is emerging. It will consider how these global challenges are affecting Ireland and also the policy issues surrounding smart grid, renewable energy and distributive generation development in Ireland. The paper will conclude that Ireland is currently well placed within the global smart grid industry and will continue to demonstrate its capability in relation to smart grid.
\end{abstract}

Keywords: Smart grid, renewable energy, distributed generation, utilities.

\section{Introduction}

In Ireland, the delivery of the 2020 and 2030 renewable energy targets is projected to result in one of the highest penetrations of variable non-synchronous generation on any power system in the world and is expected to create very challenging future operational scenarios for the grid system operators [1]. The requirement to develop an Irish smart grid, which will enable increased control over the electricity system and consequently improve the overall efficiency and reliability of the electricity supply, has therefore been pushed up the energy policy agenda and has resulted in significant national commitments to investment in electricity system infrastructure. A smart grid is an electricity network that can costefficiently integrate the behavior and actions of all users connected to it - generators, consumers and those that do both - in order to ensure economically efficient, sustainable power systems with low losses and high levels of quality and security of supply and safety [2]. Fig. 1 below provides a schematic representation of the key elements within the smart grid system.

The world is currently looking at Ireland as a leader in the Smart Grid arena, having a favorable base to become such a leader: excellent renewable energy resources; a strong engineering and ICT sector; a vibrant entrepreneurial spirit; an active research sector; a propitious corporation tax rate; a well-educated, adaptable workforce; and the convenience of having a single state owned commercial TSO (Transmission

\footnotetext{
*Manuscript received May 29, 2015; revised August 24, 2015.

Corresponding author. Tel.: 00353863625057; E-mail address: o.nicsuibhne@udaras.ie

${ }^{1}$ GREAT (Growing Renewable Energy Applications and Technologies) is an INTERREG IVB NWE funded project that aims to accelerate the deployment of Smart Grid (SG) in North West Europe. It focuses is on the provision of information to Regulatory Authorities on technological development, encourages SMEs and communities to develop technological solutions in relation to SG, Renewable Energy (RE) and Distributive Generation (DG).

doi: 10.12720/sgce.4.3.216-223
} 
System Operator) and a single semi-state DSO (Distribution System Operator); compare this to for example Germany that has 4 private TSOs and 896 DSOs. DSOs will play a key role as neutral facilitators of tomorrow's more decentralized energy system which the Smart Grid facilitates; and Irelands DSO, ESB Networks, is considered a world leader and promises dynamically managed networks that will minimize losses by 2017.

The development of smart transmission and smart distribution networks will include advanced monitoring and control systems and enable two-way communication between generators, suppliers and consumers. The advanced control systems are also expected to encourage innovation in smart home devices, which can respond to remote signals and enable their demands to be managed and aggregated by a central controller (aggregator), which will ultimately allow system operators to optimize the balance between the variations in end-user electricity demands and available electricity supply.

In addition, the advanced communications systems afforded through the roll-out of smart metering facilitate the provision of more detailed information to consumers regarding their usage and also the introduction of time of use based pricing, both of which can encourage end users to manage their demand by reducing their overall electricity usage and/or shift their demand to a time when there is a plentiful supply of low cost renewable electricity on the grid.

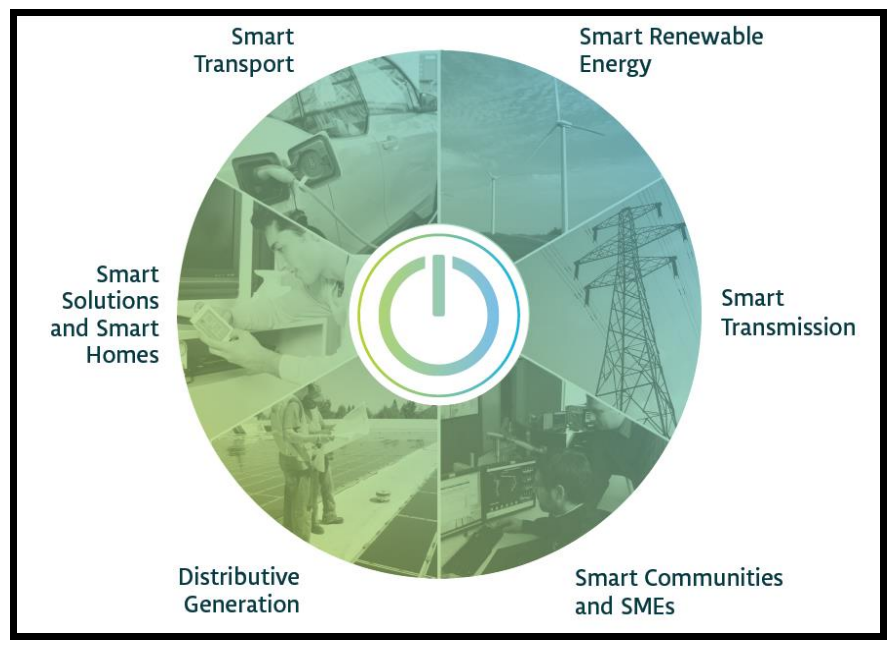

Fig. 1. Key elements of a smart grid system.

Smart meters and time based pricing signals will also enable the introduction of innovative tariffs, which can be used to improve the attractiveness of distributive micro-generation via 'feed-in' tariffs and also of electric vehicles by offering low cost night tariff to encourage charging when there is a plentiful supply of low cost renewable electricity on the grid .

Collectively these innovations are expected to encourage the development of smart communities which incorporate demand management, energy storage and distributive micro-generation technologies within a smart grid cluster. Potentially, the advanced communications and control capabilities within the smart grid could be used to facilitate power matching within these communities.

\section{Smart Grid Policy and Legislation: Europe}

In January 2007, the European Commission published "An Energy Policy for Europe", which outlined some key priorities for an EU energy policy framework [3]. These include, among others, establishing an internal energy market, ensuring security of energy supply, and reducing greenhouse gas emissions. Since 2009, European legislation and policy has prioritized the support of smart grids and in 2013 the European Commission estimated that there were 459 smart grid projects underway across the EU, involving $€ 3.15$ billion investment (excluding smart metering projects). This was made up of $26 \% \mathrm{R} \& \mathrm{D}$ and $72 \%$ 
Demonstration and Deployment projects.

\subsection{The third package on energy}

The European Union (EU) intends to build an internal market for electricity and gas, which will support the new energy policy through enabling the delivery of energy supplies that are affordable, secure and sustainable. In September 2007, the European Commission adopted the third package of legislative proposals on energy to ensure an integrated and competitive energy market and give choice of supplier and benefits to EU citizens. Member States were given 18 months to transpose the package of directives and regulations relating to electricity and gas markets ${ }^{2}$.

The Third Energy Package gave fresh impetus to the process of European electricity market integration, and has resulted in a number of key pieces of EU legislation relating to smart grids being enacted since 2009 , the most significant of which are discussed in the following sections.

\subsection{The electricity directive}

The Third Energy Package included the Electricity Directive 2009/72/EC, which amended Directive 2003/54/EC and set out rules for the internal market in electricity. The competitive internal energy market is a strategic instrument, which is designed to provide European consumers with a choice between different companies supplying gas and electricity at reasonable prices, and also to improve the market accessibility for all suppliers, especially the smallest and those investing in renewable forms of energy. Realizing the internal energy market, will however, depend on the availability of a reliable and coherent energy network in Europe and therefore on infrastructure investment, in particular in smart grids. It sets out the measures needed to unbundle the networks, facilitate cross-border access to electricity suppliers, provide incentives for investing in electricity from renewable energy sources and provide consumers with the means to use energy more efficiently.

\subsection{Energy infrastructure package (2013)}

The Energy Infrastructure package (EC) 347/2013 provides EU funding for investments in upgrading the electricity grid that are considered to be Projects of Common Interest (PCI). The PCI concept covers lines, pipelines, facilities, equipment or installations falling under the energy infrastructure categories and is defined by certain criteria: "the project is necessary for at least one of the energy infrastructure priority corridors and areas; the potential overall benefits of the project outweigh its costs, including in the longer term; and the project has to either involve at least two Member States by directly crossing the border of two or more Member States, be located on the territory of one Member State and have a significant crossborder impact or cross the border of at least one Member State and a European Economic Area country" [4]. The PCIs will be eligible for up to $€ 5.85$ billion of EU funding and for accelerated permitting through streamlined national processes.

\subsection{0 and 2030 climate targets}

Since 2008, the European Union has a package of climate change measures known as the 20-20-20

\footnotetext{
${ }^{2}$ The package included the following legislation:

Directive 2009/72/EC 13 July 2009 concerning common rules for the internal market in electricity and repealing Directive 2003/54/EC

Directive 2009/73/EC of 13 July 2009 concerning common rules for the internal market in natural gas and repealing Directive 2003/55/EC

Regulation (EC) No 713/2009 of 13 July 2009 establishing an Agency for the Cooperation of Energy Regulators

Regulation (EC) No 714/2009 of 13 July 2009 on conditions for access to the network for cross-border exchanges in electricity and repealing Regulation (EC) No 1228/2003

Regulation (EC) No 715/2009 of 13 July 2009 on conditions for access to the natural gas transmission networks and repealing Regulation (EC) No 1775/2005.
} 
targets in place. These set three key objectives for 2020:

- 20\% reduction in EU greenhouse gas emissions from 1990 levels;

- Raising the share of EU energy consumption produced from renewable resources to $20 \%$;

- $20 \%$ improvement in the EU's energy efficiency.

In 2011, the Commission's Communication on a Roadmap for moving to a competitive low-carbon economy in 2050 identified Smart Grids as a key enabler for a future low-carbon electricity system, facilitating demand-side efficiency, increasing the shares of renewables and distributed generation, and enabling electrification of transport.

The EU is making progress in achieving these objectives and has started to look on to 2030. On 23 October 2014 EU leaders agreed that 2030 European greenhouse gas emissions would be reduced by at least $40 \%$ compared with 1990 . The same climate framework has set a target of at least $27 \%$ for renewable energy and energy savings by 2030, however without specifying individual Member State targets.

\section{Smart Grid Policy and Legislation: Ireland}

Ireland's overarching vision of a low carbon future will require a fundamental change in the ways in which electricity is supplied and consumed, requiring a strong policy focus on smart grid technologies, the development and integration of renewable energy and distributive generation, and the promotion of energy efficiency. The Government has recognized these challenges and has stated that 'transforming Ireland's economy from one based on predominantly imported fossil fuel to a more indigenous low carbon economy, which is centered on energy efficiency, renewable energy and smart networks, offers great scope to address the interrelated challenges of climate change, energy security and competitiveness' [5].

In recognition of the importance of smart grid the Irish Government has supported the following initiatives:

Smart Grid Advisory Group: The Smart Grid Advisory Group was established to assist collaborative working amongst key industry players towards the vision of the Smart Grid Innovation Hub and also in support of Ireland's potential as a smart grid test bed to lead the way in evaluating and developing solutions to the energy challenges that lie ahead.

Smart Grid Roadmap: The Sustainable Energy Authority of Ireland (SEAI) has also developed the smart grid roadmap to 2050, which includes the development of market structures and polices to encourage increased electrification of potentially flexible loads; utilisation of demand side management tools to assist in reducing the peak demand requirement and also in utilising available off-peak renewable energy and the deployment of technologies that enable greater flexibility (energy storage, distributive generation and load aggregators).

Climate Change Bill: Since January 2015, the objective of a transition to a low carbon, climate resilient and environmentally sustainable economy by the end of the year 2050' has been enshrined in legislation in the Climate Action and Low Carbon Development Bill 2015. The Bill provides for the preparation, and approval by the Government, of five-yearly National Low Carbon Transition and Mitigation Plans.

National Smart Meter Programme (NSMP): Smart meters have been recognised by Government as a central component of the strategy to radically enhance management of energy demand, deliver smart networks and enable greater energy efficiency through the use of cutting-edge technology and consumer empowerment [6]. The CER has recently issued a decision paper on the national roll-out of smart meters [7]; roll-out of this technology will be key to the development of a smart grid for Ireland.

Grid 25: To facilitate the expected increase in renewable generation and to adequately meet electricity demands into the future, EirGrid (Ireland's only state owned TSO) developed the Grid25 programme. Grid25 is a $€ 3.2$ billion plan to develop and upgrade the Irish electricity transmission network through to 2025. This investment is necessary to facilitate the integration of Gate 3 renewable generation, and in particular the transportation of electricity from new on-shore and off-shore wind energy resources at the 
Atlantic seaboard to centers of consumer demand. The Grid25 project will double the size of today's electricity grid and will include $800 \mathrm{~km}$ of new power lines and the upgrading 2,000 km of existing lines [8]. This investment will increase security of supply to regions of the country that are isolated from traditional forms of power generation and provide more grid capacity to incorporate the renewable energy projects needed to meet Ireland's 2020/2030 targets.

National Energy Efficiency Action Plan (NEEAP): Ireland has a national target of $20 \%$ energy savings in 2020 (relative to the 2001-05 average), complemented by an additional target of energy reduction in the public sector by 33\% in 2020. The third National Energy Efficiency Action Plan in 2014 identifies measures that could reduce annual emissions of around 7.3Mt and save approximately $31,955 \mathrm{GWh}$ of energy 2020 [9].

\section{Smart Grid Implementation}

In Ireland the over-riding driver behind the development of smart grid is the requirement to meet the 2020 and 2030 EU targets for renewable energy. To date, progressive smart grid policy initiatives and also the commitments to smart grid infrastructural improvements have encouraged private investment in smart grid development projects in Ireland. In addition Ireland's established ICT industry and internationally-recognized academic research facilities ensure the availability of a highly skilled workforce and provide a foundation to enable Ireland to become a world leader in smart grid deployment.

The energy transformation process is also driving change within the economy, which in turn is generating a number of potential business opportunities. The development of a smart grid is expected to create a hive of activity as both indigenous and multinational companies strive to develop new technical solutions and smart applications, thus generating considerable employment potential. Indigenous Irish companies as well as multinational corporations are seeking to innovate and develop new solutions to deliver new products and, services to a rapidly growing global market for smart grid technologies.

Due to its geographical location Ireland has an abundant wind resource, particularly on the Atlantic seaboard, which provides the largest source of renewable electricity generation. However, the asynchronous, variable nature of wind means that demand must be matched to meet supply. Since, the smart grid facilitates the integration of electricity supply from a range of sources and also enables demand response, it provides system operators with the ability to balance the electricity system via a portfolio of measures, such as:

- Electricity from other renewable / distributed generation sources;

- Electricity imports and exports via inter-connection;

- Conventional generation (peaking plants);

- Integration of electricity storage;

- Demand management - demand response / load balancing / load shifting / reduction.

The development of the smart grid will enable large amounts of distributed generation and renewable wind electricity to be integrated onto the electricity system and therefore maximizes the amount of total final energy that can be delivered from renewables. The SEAI report 'Smart Grid in Ireland - A requirements review' identified a number of strategic drivers which will entail considerable modernisation and expansion of both the transmission and distribution network operations. The following are most significant:

- Integration of higher volumes of electricity from renewable energy sources (non-synchronous);

- Transportation of renewable generated electricity from large scale wind farms (rural areas) to centres of concentrated demand (urban areas);

- Utilisation of demand response and load management technologies;

- Integration of distributed micro-generation;

The current level of Government commitment to smart grid development and also the existence of a stable regulatory framework has provided investors with certainty and resulted in significant commitments to smart grid infrastructure. 


\section{National Targets}

Under Directive 2009/28/EC, Ireland is legally obliged to ensure that by 2020 at least $16 \%$ of all energy consumed in the state is from renewable sources, with a sub-target of $10 \%$ in the transport sector. This implies increasing the amount of renewable energy consumed in the electricity, heat and transport sectors from the status quo. The National Renewable energy strategy established a share of $40 \%$ renewable electricity, $12 \%$ renewable thermal energy, and 10\% renewable transport energy in Ireland for 2020 and the policies planned are detailed in the National Renewable Energy Action Plan (NREAP). These targets are challenging - while significant progress has been made, particularly in wind energy where there has been an increase in its share of electricity from $2 \%$ to $16 \%$ in 8 years, the share of renewable electricity at $21 \%$ needs to nearly double to reach the 2020 target. This is achievable if the high growth rate between 2010 and 2012 of $19 \%$ is sustained. However renewable electricity alone will not be enough; the share of renewable energy in transport and heat will also need to significantly increase to achieve $16 \%$ of final energy consumption from renewable energy.

Ireland is required to reduce energy consumption by $20 \%$ through energy efficiency measures, which entails a reduction of 31,925 GWh in final energy demand. The EU Energy Efficiency Directive also sets out a range of obligatory measures that are relevant to smart grids, such as improving the energy efficiency of public buildings, putting an obligation on energy providers to deliver energy efficiency measures with their users (with a cumulative annual end-use energy savings target of $1.5 \%$ ), empowering energy consumers to better manage consumption through access to data on consumption through individual metering, and to carry out an assessment of the potential for high efficiency cogeneration and district heating and cooling [10]. SEAI estimates that to achieve the energy efficiency $20 \%$ target $€ 1$ billion will need to be invested per year in energy efficiency in Ireland up to 2020. Demand side response, which includes energy efficiency measures, forms an increasingly important part of energy strategy to not only reduce energy consumption and demand, but also to support increased uncertainty and flexibility requirements in energy systems with higher levels of wind energy. In this context, the Single Electricity Market (SEM) states that demand side response could:

- Contribute to avoided investment in peaking plant by delivering peak load reduction;

- Avoid the curtailment of wind by increasing demand in the off-peak periods;

- Provide flexibility to mitigate the uncertainty of wind output;

- Contribute to providing frequency response and similar ancillary services at times when thermal generation does not run; and

- Help mitigate transmission and distribution network constraints.

\section{Challenges for Smart Grid Deployment in Ireland}

The challenge of meeting the EU 2020 and 2030 renewable energy targets and ultimately delivering a de-carbonized economy in 2050 will require a transformation of the energy sector and will therefore drive considerable change across the entire value chain, from the system operators through to the individual household customers. Flexibility and energy system integration will be key to enable increased penetration of renewables and demand response to the grid. These challenges are outlined below.

\subsection{Interconnection}

It is expected that increased interconnection to Great Britain and continental Europe will be required to facilitate balancing of variable renewable generation and over time the increased export of renewable generation. However, there are some concerns regarding the suitability of increased DC interconnection to the asynchronous power system in Ireland which carries large amounts of variable wind generation, as this solution is very expensive and also provides limited system services and supports which are required to balance high levels of wind. The EU Commission has advised that modern energy infrastructure is essential to enable the EU to integrate its energy market and to meet its energy and climate goals, and has 
estimated that around $€ 200$ billion investment in transmission grids and gas pipelines will be needed during the current decade [11]. This investment will include the development of a series of new interconnectors which will allow adjacent power markets to collaborate to share their generation portfolios of flexible resources, through facilitate the integration of larger volumes of variable renewables. There are currently two interconnectors from the Irish SEM to the UK, one 500kV High Voltage Direct Current (HVDC) running East-West between Ireland and Wales, and the Moyle 500kV HVDC running between N Ireland and Scotland. There are also plans to develop a second North-South interconnector within the SEM (between Tyrone and Meath $(400 \mathrm{kV})$ ) and an interconnector between Ireland and France is also under consideration.

\subsection{Public acceptance/community engagement}

Consideration must now be given as to how national energy policy and legislation could be adapted to create a proactive environment to support the development of smart grid in Ireland. Fundamentally, a fair, open and just decision-making process for agreeing policies and project specific consents for wind energy projects will be central to the long term deployment of wind energy in Ireland [12].

As the public mood shifts, there is a need to reflect on how policy and practice can be changed to support community acceptance of energy infrastructure projects. In recent years, some initial research has been carried out on what will be needed to engage communities and citizens in both the national energy debate and in acceptance of local energy infrastructure development. Reports commissioned by National Economic and Social Council (NESC) [13], SEAI [14], and Irish Wind Energy Association (IWEA) [15] have outlined the challenges and proposed some solutions to the opposition to wind energy development in some communities. They all show that the right enabling conditions for community acceptance are needed that address issues such as:

- Ownership structure

- Regulatory support mechanisms (financial \& others)

- Technological characteristics of renewables for the local area

- Economic characteristics of renewables in the area.

NESC point out that there are three elements to encouraging social support for renewable energy projects:

- An overarching energy-transition process that facilitates and guides society-wide efforts to transform energy systems such as that in Germany and Denmark which were intentional, participatory and problem-solving processes. An integral component of the process is a national discussion, informed by international best practice, about how to design an energy strategy in line with society's goals.

- An effective and inclusive process of public participation that helps to shape and share local value and that that brings expertise together, facilitates exploration and executes possibilities is critical. Communities that contribute to and shape the local value of energy are more likely to be supportive of future developments.

- Enabling organisations, and, in particular, intermediary actors, which support the kind of problemsolving and entrepreneurialism necessary to initiate renewable-energy developments.

The Green Paper on Energy Policy in Ireland published for consultation by the Department of Communications, Energy and Natural Resources (DCENR) on the Energy Transition for the five year period from 2015 has recognised that building societal acceptance is an important challenge in further deploying renewable energy [6]. A number of questions regarding the engagement and empowerment of energy citizens are raised, such as how to encourage citizens to be part of the transition to future energy paths, and the appropriate policy-making process needed, including the right mechanisms to engage citizens with regulatory and policy decisions. The White Paper on Energy Policy in Ireland will be published later in 2015. It will include policies and key actions to support the engagement of citizens in the energy transition, raise awareness of the future energy issues and enable more community empowerment. 


\subsection{Renewables connection to the grid}

Connections of large volumes of embedded and particularly variable generation has a significant impact on the design, operation and cost of electricity transmission and distribution systems. Because of the island nature of Ireland's electricity system, Ireland was one of the first locations to realize the impact of greater network constraint and congestion that variable generation can cause and a moratorium on the granting of grid connections was issued in 2003. This led to the creation of the group processing method of analysing and granting grid connections called Gate Processing. The Gate system was introduced by the CER in 2004 to allow for strategic processing of batches ("gates") of generation applications for grid connection by system operators (EirGrid and ESB Networks). Assessing a group of projects together allows for more efficient construction and costing of grid connections. Access to a Gate is by date of application, an objective criterion, however renewable developers have criticised the transparency of the studies done to determine timing of construction and connection cost. The most recent round of connection offers were issued under 'Gate 3' between December 2009 and June 2011 and included offers for 3,900 MW wind generation and 1,700 MW conventional generation. At the time it was envisaged that the collective offers made through the successive gate processes (1, 2 and 3) would enable Ireland to meet its $40 \%$ renewable generation target. However, the construction of both new onshore wind generation and the necessary supporting infrastructure has been met with increasing opposition from local communities (as detailed in the previous section 6.2) which has resulted in a number of Gate 3 renewable generation offers not progressing through the planning phase.

\subsection{Integrated single electricity market (I-SEM)}

The I-SEM is an energy-only market, reflecting the short-run marginal costs of generation, and which will require electricity generators and suppliers to forecast their generation and consumption and to bid at the price at which they are prepared to buy and sell. There are several levels of energy trading arrangements included within the I-SEM, beginning with the forward market to facilitate long term hedging, through the day-ahead and intra-day markets to balancing and dispatch mechanisms.

The market includes increased risk for generators and suppliers as they will be financially responsible for ensuring that their actual physical generation and demand matches their forecasted figures. However, the European Commission consider that these risks are expected to be offset by the benefits of additional competition and the efficiencies gained through intra-country trading within the EU. Nonetheless, participants of the electricity market in Ireland are raising questions as to the suitability of the I-SEM to a small market on the periphery of Europe with a high wind output. In particular the proposed capacity payments and system services mechanisms may be challenging in the Irish context, as they are both bidding-based and are therefore best suited to dispatchable generation rather than variable wind generation.

The European Commission has also recognized that within Internal Energy Market in the EU each Member State will be characterized by a set of unique circumstance and there is leeway to design national policy taking this into account. The challenge for Ireland is therefore to develop policies with the I-SEM that match these requirements in order to facilitate maximum utilization of its indigenous renewable energy resources while meeting the conditions of the Internal Energy Market. The High Level Design of the I-SEM was published by the SEM in September 2014, however, it is not until the detailed design is further developed over the next two years that participants will know how the key elements of the new market will impact upon day-to-day trading for electricity generators and suppliers.

\subsection{Distributed generation and local microgrid development}

The regulatory framework needs to be conducive to investment in smart grids. This means it should encourage the network operator to earn revenue through efficiency gains and lower peak investment needs rather than additional sales of energy. Collectively these innovations are expected to encourage the development of smart communities which incorporate demand management, energy storage and 